\title{
TRADUCCIONES CATALANAS DE TEXTOS CIENTÍFICOS ANDALUSÍES EN LA CORONA DE ARAGÓN
}

\author{
Expiración GARCÍA SÁNCHEZ \\ C.S.I.C. Granada
}

\section{INTRODUCCIÓN}

Durante la amplia etapa histórica que abarcan los reinados de Jaime II (1291-1327) y Pedro IV ${ }^{1}$ (1336-1387) se llevó a cabo en la Corona de Aragón, bajo el impulso de estos dos monarcas, un importante programa de traducciones al catalán de obras cientificas árabes.

En efecto, durante este período encontramos una serie de factores de muy diversa índole que van a conformar el ambiente históricocultural y que, auspiciados de manera muy directa por ambos gobernantes, van a dar lugar a un importante movimiento científico en el que los elementos orientales desempeñarán un papel de primer orden. Esta cultura de signo predominantemente medieval, con una notable influencia oriental que caracteriza la época de Pedro el Ceremonioso, va a dar paso en el reinado de su hijo y sucesor, Juan I, a una corriente de tipo humanista.

Hay constancia de monarcas anteriores a Pedro IV que demostraron un gran interés personal y, al mismo tiempo, ejercieron una importante labor de mecenazgo en diversos campos cientificos, promoviendo toda una serie de traducciones y estudios de astronomía, medicina, matemáticas y agronomía, todos ellos de tradición oriental. Esta marcada

${ }^{1}$ No se debe confundir a este monarca -IV de Aragón y III de Cataluña-, como se ha hecho en bastantes ocasiones, con Pedro III el Grande, que reinó desde 1276 a 1286. 
inclinación hacia la cultura oriental no fue privativa de los monarcas, sino que se hizo patente también en una serie de miembros de la nobleza y el clero. Tal es el caso del arzobispo Sancho de Aragón, hijo de Jaime el Conquistador, que reunió un número muy estimable de manuscritos relativos a diversas ciencias naturales, de ellos varias traducciones del árabe al latín ${ }^{2}$.

El embrión de esta labor traductora de obras científicas hay que situarlo a mediados del siglo $\mathrm{X}$ en los centros monacales ubicados en la Marca Hispánica y que, a partir del ejemplo de Ripoll y más tarde de Vich, se fue extendiendo a otros centros europeos y diversos núcleos urbanos del valle del Ebro y la frontera pirenaica. De todos es sobradamente conocido el valor de estas traducciones latinas de textos árabes y hebreos como elemento de conservación y, al mismo tiempo, de difusión de la cultura oriental en los medios europeos, para insistir sobre ello ${ }^{3}$.

Volviendo con la actividad científica desplegada por los monarcas de la Corona de Aragón, no hay que olvidar que Jaime II mantuvo frecuentes relaciones con el reino de Granada y las cortes norteafricanas, lo que, unido a la protección que dispensaba a una serie de familias judías cuyas excelentes dotes como traductores siempre fueron proverbiales, influyó decisivamente en el desarrollo en los territorios de la Corona de esta corriente de impronta oriental. Efectivamente, los judíos cultos medievales normalmente conocían -y en muchos casos poseían un perfecto dominio-, aparte del hebreo, el árabe, las lenguas romances peninsulares, e incluso el latín, como es el caso de Abraham b. Ezra o de los colaboradores judaicos en la corte de Alfonso $\mathrm{X}$ el Sabio. Entre estas familias destacan los Bonsenyor, los hermanos Bellshom y Vidal Efraim, Abraham Cresques y su hijo Yafuda ${ }^{4}$.

${ }^{2}$ Cf. J.M. Millás Vallicrosa, Las traducciones orientales en los manuscritos de la Biblioteca Catedral de Toledo, Madrid, 1942, págs. 15-17.

${ }^{3} \mathrm{~J}$. Vernet, La cultura hispanoárabe en Oriente y Occidente, Barcelona, 1978, pág. 106 y ss.

${ }^{4}$ Sobre la actividad desarrollada por estas familias judías, cf. J.M. Millás Vallicrosa, Las Tablas astronómicas del rey Don Pedro el Ceremonioso, edición crítica de los textos hebraico, catalán y latino, con estudio y notas, MadridBarcelona, 1962, págs. 77-84. 
Además, hubo importantes centros traductores, ubicados todos en las aljamas judías, entre las que destacan las de Toledo, Guadalajara y Barcelonas.

Este progresivo interés por conocer la producción cientifica árabe y clásica -ésta última también a través de versiones árabes- se deja sentir en el aumento de obras y de temas traducidos, al mismo tiempo que el latín y el hebreo pierden su exclusividad como lenguas de las traducciones para dejar paso a las versiones romanzadas, realizadas en diversos núcleos peninsulares, siempre dependientes de comunidades judías; el catalán se va introduciendo como sustitutivo del latín, que ya desde finales del XII, y como un fenómeno extensivo a todo el territorio peninsular, había ido comenzando a declinar como lengua de las traducciones cientificas.

\section{ACTIVIDAD TRADUCTORA DESARROLLADA EN LA CORONA DE ARAGÓN (s. XIV)}

A raíz de la fundación del Estudi General de Lérida en 1300, Jaime II fomentó la incorporación de la medicina árabe a la Corona de Aragón. El mismo año de su fundación, el monarca dio orden de que se entregaran varios libros de medicina árabe a Maestre Guillem Jaubert de Beziers, lector de medicina de aquella Universidad ${ }^{6}$; también dispuso la compra de dos obras de Avicena $y$, aunque no se indica título, pienso que alguna de ellas sería el famoso Canon? ${ }^{7}$ En este sentido, debemos recordar -a título indicativo- que en la Corona de Aragón se tradujeron, entre los siglos XIII y XV, unas 46 obras médicas del árabe al hebreo, latín y catalán.

${ }^{5}$ Especial importancia revistió la aljama de Toledo, en la que se redactaron - copiaron en árabe manuscritos médicos hasta el año 1424. Cf. L. García Ballester, Historia social de la medicina en la España de los siglos XIII al XVI. Volumen I: La minoría musulmana y morisca, Madrid, 1976, págs. 31-34.

- Cf. J.M. Millás Vallicrosa, Las tablas astronómicas, págs. 56 y 57.

${ }^{7}$ A. Rubió y Lluch, Documents per l'historia de la cultura catalana migeval, 2 vols., Barcelona, MCMVIII, II, doc. $n^{\circ}$ XIX y XXVI, págs. 15 y 20, respectivamente. 
Así, hay que destacar un documento de 1313 en el que se recoge la orden dada por este mismo monarca -Jaime II- para que se pague al judío Yafuda Bonsenyor la traducción al romance de un "libro scripto in arabico medicine vocato halçahany"8. De acuerdo con la teoría de A. Cardoner, seguida por otros investigadores, entre ellos Millás Vallicrosa, se trataría de la traducción de una parte del Kitäb al-Tașrif, la magna obra enciclopédica del médico cordobés del s. X, al-Zahrā$\mathrm{wi}^{\mathrm{9}}$. Posiblemente sea la Maqăla XXVIII, que fue traducida al latín con el título de Liber servitoris, o bien la XXX, dedicada a los instrumentos quirúrgicos, ya que ambas alcanzaron una enorme difusión. Sin embargo, no se ha conservado ningún ejemplar de esta versión catalana que pueda corroborar o desechar tal hipótesis ${ }^{10}$.

Por su parte, Pedro IV mandó unas veces comprar y otras traducir al catalán -arromançar, tal como aparece en la documentación de su época- una serie de libros escritos en árabe ${ }^{11}$, aunque sólo conocemos los títulos de algunos de ellos. Las obras que dispuso traducir, todas ellas de carácter científico, se pueden agrupar, fundamentalmente, en los temas siguientes: astronomía, agricultura, matemáticas y medicina, junto a otras sobre astrología.

No obstante, fue la astronomía, tema por el que el monarca sentía una marcada inclinación, la que recibió una mayor atención; de modo especial, se interesaba por las aplicaciones y "utilidades" astrológicas, de acuerdo con las creencias generalizadas del momento. Asimismo, y dado que las tablas astronómicas que circulaban en su época, especialmente las de Toledo o de Azarquiel y las del rey castellano Alfonso $\mathrm{X}$ -las Tablas Alfonsíes- ${ }^{12}$, ya adolecían de ciertos errores y deficiencias,

${ }^{8}$ Ibidem, II, doc. $n^{\circ}$ XXIX, pág. 22.

9 A. Cardoner Planas, "Nuevos datos acerca de Jafuda Bonsenyor", Sefarad, IV (1944), 287-293, especialmente las páginas 291-293.

10 Parece ser que se perdió esta traducción del árabe al catalán, lo mismo que sucedió con otras realizadas por Benvenist Abenvenist, también llamado Vidal Benvenist de Porta. Cf. Ibidem, págs. 290-292.

11 A. Rubió y Lluch, Documents, I, $\mathrm{n}^{\circ}$ CXXXVI, págs. 142 y $143 ; \mathrm{n}^{\circ}$ CXXXVIII, pág. 143; n CLIV, págs. 155 y 156; n CLXII y CLXIII, págs. 163 y 164 , entre otros documentos.

${ }^{12}$ Sobre ambas obras, cf. J.M. Millás Vallicrosa, Estudios sobre Azarquiel, 
encargó al astrónomo palatino Pedro En Gilbert y a uno de sus discípulos la redacción de unas nuevas tablas, calculadas en Barcelona, en las que incorporaran sus propias observaciones ${ }^{13}$.

Otro de los temas escogidos, aunque ello no haya sido puesto de relieve hasta ahora, fue la agronomía. Resulta curioso el interés demostrado por algunos reyes, de distintas épocas y zonas peninsulares, hacia los textos agrícolas andalusíes, promoviendo su difusión, ya sea a través de la traducción a lenguas romances -tal es el caso de Alfonso $\mathrm{X}$, Jaime II y Pedro IV- o, ya en época más tardía, por medio de su edición -caso de Carlos III-, hecho que viene a constatar el reconocimiento del alto nivel de desarrollo alcanzado por la agricultura en alAndalus ${ }^{14}$.

Así, en el programa cultural llevado a cabo por el Rey Sabio se tradujeron al castellano los textos agrícolas de dos autores toledanos del siglo XI, Ibn Wāfid e Ibn Bașșāl ${ }^{15}$, aunque nos han llegado en un códice tardío y fragmentario, el $\mathrm{n}^{0} 10.106$ de la Biblioteca Nacional de Madrid, procedente de los fondos de la Biblioteca Catedral de Tole$\mathrm{do}^{16}$. Siglos más tarde, ya mediado el XVIII, se puso en marcha un ambicioso programa auspiciado por la monarquía y destinado a recuperar los conocimientos agrícolas y botánicos contenidos en diversas obras andalusíes depositadas en la biblioteca del monasterio de El Escorial. Uno de sus frutos fue la edición y traducción al castellano, realizadas por J. A. Banqueri, del Kitäb al-filahha (Libro de agricultura)

Madrid-Granada, 1943-1950.

13 J. M. Millás Vallicrosa, Las tablas astronómicas, págs. 20 y 21.

${ }^{14}$ Tales tratados agronómicos fueron los de Ibn Bașăl, Ibn Wāfid -éste en la doble versión, castellana y catalana-e Ibn al-'Awwäm, respectivamente.

${ }^{15}$ E. García Gómez, "Traducciones alfonsíes de agricultura árabe", BRAH, tomo CLXXXI, cuaderno III (sep.-dic. 1984), págs. 387-397, confirma la hipótesis, ya apuntada por Millás, de que ambas versiones son alfonsíes. No obstante (pág. 395), rechaza que el texto atribuido a Ibn Wāfid sea realmente de este autor y lo incluye dentro de los textos agrícolas de "la escuela sevillana".

${ }^{16}$ El texto de ambas versiones castellanas medievales ha sido editado por J.M. Millás Vallicrosa, "La traducción castellana del "Tratado de Agricultura" de Ibn Wäfid", Al-Andalus, VIII (1943), págs. 281-332, y "La traducción castellana del "Tratado de Agricultura" de Ibn Bașsāl", Al-Andalus, XIII/2 (1948), págs. 347-430. 
del sevillano Ibn al-'Awwām (s. XII-XIII), obra que ha constituido durante largo tiempo la única referencia sobre la agronomía andalusi ${ }^{17}$.

Retrotrayéndonos al siglo XIV, vemos cómo vuelve a aflorar el interés de los monarcas, en este caso de la Corona de Aragón, por las obras de los agrónomos andalusíes, como lo atestiguan determinados documentos.

En la colección documental publicada por Rubió se encuentra, registrado con el $\mathrm{n}^{\circ} \mathrm{CCX}$ y fechado en 1363, el siguiente documento real:

\begin{abstract}
"Lo rey.
Com, segons havem entes, vos tingats un libre ab cubertes verts scrit en paper, lo qual tracte de agricultura e lo qual fou compilat per Mirababoli, moro rey qui fo de Sibilia, e en la fi del qual libre es escrit lo regiment de Aristotil, e nos desigem molt haver lo dit libre; per ço us pregam que del dit libre fassats fer un traslat..."
\end{abstract}

Esta obra ha sido identificada, aunque con reservas -Millás, Rubió-, con el citado Kitab al-filah̆a de Ibn al-'Awwäm, aunque no tenemos dato alguno que nos pueda confirmar esta identificación. Sólo la ciudad de Sevilla, cuna del autor y del pretendido rey que mandó compilar el tratado, aparece como el único punto coincidente, aunque ello no representa una prueba definitiva. Este rey -Mirababoli- debe referirse a alguno de los gobernantes de la dinastía almohade, quienes adoptaron el título honorffico de $A m i r$ al-mu'minin, normalmente traducido en las fuentes castellanas como "Miramamolín"; o, incluso, podría aludir a alguno de los soberanos almorávides que, a su vez, se hicieron nombrar Amir al-muslimin. Tampoco tenemos noticias de que Ibn al-'Awwām escribiera su obra por encargo de nadie, asI como tampoco ésta tiene

17 Precisamente, esta obra se reimprimió en 1988, con motivo de la conmemoración del bicentenario de la muerte de Carlos III, monarca que, junto a otros miembros de su gobierno, demostró un abierto interés por recuperar los textos clásicos agrícolas. Ibn al-'Awwām, Libro de agricultura, ed. y trad. cast., J.A. Banqueri, 2 vols., Madrid, 1802, edición facsímil, con estudio de E. García Sánchez y J.E. Hernández Bermejo, Madrid, 1988.

${ }^{18}$ A. Rubió y Lluch, Documents, I, nº CCX, pág. 205. 
carácter de resumen, a no ser que por resumen se entienda el gran acopio de fuentes que realiza en ella. No obstante, G. Sarton, entre las diversas obras árabes que Pedro el Ceremonioso mandó traducir al catalán, hace referencia a "notably a book of agriculture"19, sin especificar título, cita esta que, muy posiblemente, ha sido la que ha inducido a tal identificación ${ }^{20}$.

De los tratados agrícolas andalusíes redactados con anterioridad al de Ibn al-'Awwām, sólo tenemos noticia de que se resumieran -sin que ello se hiciera por encargo de nadie- poco después de su redacción original los de Ibn Bașșāl y al Tignarī, quienes los dedicaron a alMa'mūn de Toledo y al príncipe almorávide Abū l-Tạhir Tamīm b. Yūsuf b. Tāsfinn, respectivamente, con lo cual queda totalmente descartado Ibn Bașsāal. Ambos agrónomos, sobre todo el granadino, residieron en Sevilla durante un largo período y también se da la circunstancia de que el hijo de Yūsuf b. Tāsfin ocupó el cargo de gobernador de Sevilla durante dos años (1122-1124), con lo cual podría pensarse, salvando la incorrecta interpretación de algunos de los datos referidos en el citado documento, que se refiriera al Kitäb Zuhrat albustān de al-Tignari ${ }^{-21}$. No obstante, no contamos con ningún elemento sólido que nos pueda conducir a una confirmación de esta hipotesis y, por tanto, seguimos sin conocer cuál fue esta obra agrícola andalusí que Pedro IV mando traducir al catalán.

Otra obra de carácter agronómico -aunque no andalusí- que este rey mandó romancear, ésta a partir del latín, fue De re rustica de Paladio $^{22}$, tratado que, al parecer, se convirtió en objeto de numerosas traducciones, algunas de ellas tan literales que obligó a algunos autores,

${ }^{19} \mathrm{G}$. Sarton, Introduction to the History of Science, 3 vols. en 5 tomos, Baltimore, 1927-1948, III/2, págs. 1072 y 1162-1163.

${ }^{20}$ J.M. Millás Vallicrosa, Las tablas astronómicas, pág. 63, apunta la posible identificación con el tratado de Ibn al-'Awwām, hipótesis que no comparto por las razones expuestas hasta ahora.

${ }^{21}$ Sabemos que al-Tignari dedicó su tratado a Tamím en los primeros diez años del siglo XII, pero durante uno de sus mandatos como gobernador de Granada, no de Sevilla. Cf. E. García Sánchez, "El tratado agrícola del granadino al-Tignari", Quaderni di Studi Arabi, 5-6 (1987-1988), págs. 278-291.

22 A. Rubió y Lluch, Documents, I, nº CXCII, págs. 272 y 273. 
caso de Ferrer Sayol, protonotario de la reina Leonor, a realizar una nueva versión que resultara inteligible ${ }^{23}$.

Por último, hay constancia de que Pedro el Ceremonioso dispuso que se tradujera al catalán, aunque ignoramos cuál sería la lengua del original, la obra llamada "Antholius". El documento, fechado en 1370, que recoge este dato reza asi:

\begin{abstract}
"Entes havem que vos havets lo libre appellat Antholius, e com nos vullam haver treslat $d$ aquell, per ço us pregam e us manam que nos façats fer treslat del dit libre e aquell nos trametats de continent que sia acabat, car nos vos farem pagar ço que costara d escriure, e certificam vos que $d$ aço ns farets plaer" ${ }^{\prime 24}$.
\end{abstract}

Dicha obra, como a primera vista podría parecer, no es el tratado agrícola de Vindanio Anatolio de Berito (s. IV-V), autor de una obra compuesta de catorce libros, Synagoge georgikon epitedeumaton, traducida al árabe y al siríaco, y de la que se han realizado una edición y una traducción castellana ${ }^{25}$. En realidad, como ha quedado totalmente demostrado en un reciente trabajo $0^{26}$, se trata de la versión, en este caso catalana, del Compendio de Agricultura (Maymü' ft l-filaha) atribuido al famoso médico toledano Ibn Wāfid (s. XI), sobre la que volveremos más adelante. En esta obra son muy frecuentes las citas a nombre de Anatolio, por lo que es posible que se pensara que él era el autor y no una de las fuentes ${ }^{27}$.

23 J.M. Nadal i M. Prats, Història de la Llengua Catalana, pág. 452. Esta nueva versión se inició en 1380.

${ }^{24}$ Cfr. A. Rubió y Lluch, Documents, I, n ${ }^{\circ}$ CXXXXIII, pág. 225.

${ }^{25} \mathrm{M}^{\mathrm{a}} \mathrm{C}$. Vázquez de Benito, El manuscrito $n^{\circ} \mathrm{XXX}$ de la Colección Gayangos (fols. 1-98), Madrid-Barcelona, 1974.

26 J.Ma Carabaza, "Una versión catalana de un tratado agrícola andalusí", Ciencias de la Naturaleza en al-Andalus", E. García Sánchez (Ed.), vol. III, Granada, 1994, págs, 169-192.

${ }^{27}$ Esto mismo le sucedió al historiador Ibn Jaldūn con respecto a la obra de Ibn al-'Awwäm, que la confundió con la Agricultura Nabatea, la magna obra enciclopédica, traducida al árabe en el s. X, que recoge todos los conocimientos agronómicos nabateos. Cf. Ibn Jaldūn, al-Muqaddima, ed. M. Quatremère, 3 
Del original árabe de esta obra se hizo también, como más arriba se ha expuesto, una traducción castellana medieval, incluida junto con la de Ibn Bașșāl, dentro del grupo de las traducciones alfonsíes; desgraciadamente, tanto el texto árabe como la traducción castellana de ambas obras nos han llegado incompletos ${ }^{28}$.

A la vista de estas versiones de textos andalusíes a lenguas romances peninsulares constatamos, aunque no conocemos las motivaciones de tal hecho, que Ibn Wãfid fue uno de los autores andalusíes preferidos por los traductores de la Corona de Aragón, ya que otra de sus obras, el Tratado de los medicamentos simples (Kitâb al-adwiya almufrada), de la que se desconoce el original árabe, aunque hay una versión aljamiada, en caracteres hebraicos, se tradujo también al catalán en esta misma época y entorno ${ }^{29}$.

vols., París, 1858, III, págs. 120 y 121 ; trad. franc., M. de Slane, 3 vols., París, 1868, III, págs. 165 y 166.

${ }^{28}$ Del resumen del original árabe de la obra de Ibn Bașạal contamos con una edición y traducción castellana: Ibn Bassāl, Kităb al-filăha, ed., trad. y anot., J. M. Millás Vallicrosa y M. Aziman, Libiro de Agricultura, Tetuán, 1955.

Por otra parte, el original árabe del tratado de Ibn Wāfid aparece recogido, también en forma incompleta, en dos ediciones de textos agrícolas andalusíes de carácter misceláneo, aunque los editores atribuyen cada tratado a un solo autor -Abū l-Jayr e Ibn Haŷyāŷy respectivamente-. Estas dos ediciones son: Abū l-Jayr al-Andalusī, Kitäb fi l-filaha, ed. Sìdi Tuhāmī, Fez, 1358 a.H.; Ibn Haŷyāŷ̀ alIšbilì, al-Muqni' fi l-filăhà, ed. Ș. Ŷ̀irār y Ŷ. Abū Șafiya, 'Ammām, 1982 (el tratado de Ibn Wäfid comprende, respectivamente, las págs. 6-84 y 2-86 de ambas ediciones). La traducción castellana la ha realizado J. $\mathbf{M}^{*}$ Carabaza Bravo, Ahmad b. Muhammad b. Haŷŷây al-Išbtit: al-Muqni' fil-filaha, introducción, estudio y traducción, con glosario, 2 vols., Universidad de Granada, 1988, I, págs. 178281. En cuanto a la traducción castellana medieval de ambas obras, publicadas por J.M. Millás Vallicrosa, cf. supra, n. 16.

${ }^{29}$ Fue editada por L. Faraudo de Saint Germain, El "Libre de les medicines particulars", versión catalana trescentista del texto árabe del "Tratado de los medicamentos simples" de Ibn Wafid, Barcelona, 1943. 


\section{MANUSCRITOS CATALANES DE LA BIBLIOTHẼQUE NATIONALE DE PARÍS}

La colección de manuscritos "espagnoles et portugaises" de dicha biblioteca contiene unos valiosos fondos, al parecer no lo suficientemente explorados, algunos de gran interés para analizar el tema de las versiones catalanas de textos cientificos andalusíes. Entre ellos se encuentra un códice misceláneo, el $\mathbf{n}^{0} 93$, que contiene, de acuerdo con el catálogo de A. Morel Fatio, tres obras, todas ellas de tema agríco$\mathrm{la}^{30}$, afirmación no del todo correcta. Estas obras, de acuerdo con dicha catalogación, son las siguientes:

La primera, "De re rustica" (fols. 1-30v), anónima, está dividida en ochenta y dos capítulos.

La segunda, "De agricultura Paladi" (fols. 30v-62r), comprende cinco libros.

La tercera (fols. 62r-130r) lleva por título: "De agricultura, altra obra".

Las dos primeras son descritas detalladamente por Morel Fatio, cosa que no sucede con la última, de la que, aparte de señalar el incipit y el explicit, se limita a indicar que "dans cette derniere compilation, qui traite de la plantation des arbres et de la vigne, de l'élevage de divers animaux et de la préparation de plusieurs remèdes, les autorités les plus souvent citées sont Antolio (Anatolius?) et Demicrates (Democrates?) $^{\text {"31 }}$.

Algunos aspectos de este códice fueron estudiados después por $\mathrm{W}$. Mettmann $^{32}$, aunque no han quedado lo suficientemente aclarados. Uno de ellos se refiere al contenido del tercer tratado, en el que me voy a detener ${ }^{33}$. Dicho profesor puntualizó que éste contenía dos obras, no

${ }^{30} \mathrm{~N}^{\circ} 291$ de la catalogación de 1860; Anc. fonds., n $n^{\circ} 8088$. Cf. A. Morel Fatio, Catalogue des manuscrits espagnols et des manuscrits portugais, terminé en collaboration avec M.Ch. Baudon de Mony, París, 1892, págs. 332 y 333.

${ }^{31}$ Ibidem, pág. 333.

32 W. Mettmann, "Eine Übersetzung des "Kompendiums" von Ibn Wafid und andere altkatalanische Texte über die Landwirtschaft", Romanische Forschungen, 92 (1980), págs. 350-358.

${ }^{33}$ Un primer avance del contenido de este misceláneo, especialmente de la 
una sola como pretendía Morel Fatio, el Tratado de agricultura de Ibn Wäfid (fols. 62r-111r) y, tras él, un libro de dietética titulado De la remenbrança de les viandes (fols. 111r-130r). Sin embargo, no pudo aclarar quién era el autor de dicho tratado dietético y, por tanto, éste siguió en el anonimato, aunque ahora ya sabemos que se trata del Kitäb al-agdiya del médico sevillano Abū Marwān 'Abd al-Malik b. Zuhr (m. 557/1162) -el Avenzoar de los textos latinos-, obra que alcanzó una gran difusión y gozó de un merecido prestigio.

Precisamente, el manuscrito árabe de París que he seguido como base en la edición que de esta obra he realizado, está copiado en Barcelona a finales del mes de safar de 562 (segunda mitad de enero de 1167 ), presumiblemente en alguna de sus aljamas ${ }^{34}$. Por este motivo, es fácil que se hicieran varias copias, alguna de las cuales sería el original sobre el que se realizaría la versión catalana.

Esta obra aparece en el códice parisino a continuación del tratado de agricultura de Ibn Wāfid, sin ningún tipo de separación que permita distinguir que son dos obras distintas; es más, el capítulo final de una y el inicial de otra aparecen numerados correlativamente. Posiblemente se trate de uno de los tratados médicos, antes aludidos, que mandó traducir Pedro IV, sin que de ellos se citara título ni autor.

Este hecho podría ser indicativo de que nos hallamos ante una copia realizada por alguien que tuvo a su alcance varios originales árabes de temas diversos -agrícolas y médicos-, que resumió y mutiló a su antojo.

Otro de los puntos en discordia relativos a este misceláneo es la fecha de redacción de estas dos últimas obras contenidas en el mismo, para la que existen varias propuestas: siglo XVI para A. Morel Fatio y $\mathrm{XIV}$ o $\mathrm{XV}$, aunque sin aportar argumentos convincentes, para $\mathrm{W}$ :

tercera de sus obras, constituyó la ponencia que presenté en el I Col-loqui de l'alimentació à la Corona d'Aragó (Lleida, nov, 1990), con el título: "La traducción catalana medieval del Kitāb al-Agdiya (Tratado de los alimentos) de Avenzoar", cuyas Actas aún se encuentran en prensa en el momento de entregar este original.

34 Abū Marwān 'Abd al-Malik b. Zuhr, Kitåb al-Agdiya Tratado de los alimentos), edic., trad. e introduc., Expiración García Sánchez, Fuentes ArábicoHispanas, 4, Madrid, 1992. Acerca de estas copias manuscritas y las diferentes versiones de la obra, puede verse la Introducción, págs. 17-41. 
Mettmann. Ahora bien, el problema estriba en que hay que deslindar la datación del original catalán de la de la copia, cosa que no han hecho ninguno de estos dos autores, originando con ello la consiguiente confusión. Pienso que la copia del códice parisino, en letra góticocursiva, data de finales del XV o comienzos del $\mathrm{XVI}^{35}$, si bien la redacción del original del tratado agrícola, a partir del cual se hizo ésta $\mathbf{u}$ otra anterior, tuvo lugar en el reinado de Pedro IV, como ha quedado aclarado. La Remenbrança de les viandes es muy posible que también se redactara en esta época, aunque ello no lo podemos afirmar con la misma seguridad absoluta con que lo hacemos del texto agrícola.

\section{A. De la Remenbrança de les viandes}

El original árabe consta, al menos, de dos partes bien diferenciadas: una primera, que sería el tratado de los alimentos propiamente dicho, y otra segunda que contiene un verdadero tratado de higiene o kitāb alsihha en el que se tratan todas y cada una de las sex res non-naturales que incluyen este tipo de obras. Lo completan una serie de temas que muy bien pueden ser extractos de otros escritos de Avenzoar.

Por lo que atañe a la traducción catalana, más que resumen, podríamos decir que se trata de un extracto del original aunque, de acuerdo con los títulos de los capítulos que contiene ${ }^{36}$, se aprecia claramente que no se ha seguido ningún criterio lógico -al menos así me lo parece- en la selección de los temas a tratar.

Por un lado, se citan los diversos tipos de pan, atendiendo al tipo de harina -de cereal o leguminosas- empleada, y a las diversas formas de elaboración. Junto a este alimento básico, otro grupo de platos que ocupaban un lugar preponderante en las dietas habituales de la gran masa de la población a lo largo de la Edad Media: las sopas espesas, gachas y potajes.

En el apartado de las carnes, el autor de la Remenbrança de les viandes presta gran atención a las de volátiles y productos derivados

35 Esta opinión también es compartida por J. Carabaza, "Una versión catalana", págs. 170 y 171.

${ }^{36}$ La relación del contenido de los distintos capítulos y apartados que contiene la obra la presento en la Ponencia antes aludida. Cf. supra, n. 33. 
-huevos- y solamente cita, dentro del grupo de ganados, las de oveja. No recoge ninguno de los restantes grupos de alimentos citados en el original árabe: pescados, frutas y verduras, leche y productos lácteos y, por último, productos endulzantes.

Por otra parte, resulta extraño el excesivo interés que muestra por los jarabes, electuarios y demás preparaciones farmacológicas. En definitiva, seguimos sin encontrar unos criterios coherentes en la selección de temas por parte del traductor.

\section{B. De Agricultura}

Hay que hacer constar que, igual que sucede con la versión castellana medieval de esta obra de Ibn Wāfid, la catalana también nos ha llegado incompleta, aunque ésta es más extensa, en bastantes ocasiones, que aquélla. Por ello se ha pensado que el texto catalán se basa en una copia castellana anterior a la que hoy conocemos, pues cubre algunas lagunas que presenta el texto alfonsí, aunque ello puede deberse simplemente a pérdidas en la transmisión de ambas versiones, ya que, en varios pasajes, la traducción castellana suple epígrafes que no se hallan en el texto catalán ${ }^{37}$.

No obstante, no podemos desechar la posibilidad de que el traductor catalán tuviera también en sus manos el original andalusí, como podemos constatar que sucedió con la Remenbrança. Prueba de ello es el literalismo de que adolecen tales versiones que, a veces, las hace oscuras e, incluso, ininteligibles, aunque, en honor a la verdad, hay que destacar, en general, la gran escrupulosidad y fidelidad de aquellos traductores árabes y hebreos. Estos rasgos pueden verse reflejados en algunos casos concretos como pueden ser:

- El uso reiterado de la conjunción copulativa $e$.

- La transposición del complemento directo.

- La concordancia del colectivo en plural.

- Empleo del partitivo, entre otros.

${ }^{37}$ Estos pasajes se encuentran estudiados en el trabajo de J. Ma Carabaza, "Una versión catalana", pág. 184, por lo que no incido en ellos. 


\section{ANÁLISIS DE ALGUNOS TÉRMINOS}

En este apartado quiero reflejar algunos de los arabismos -o posibles arabismos en otros casos- registrados en ambas obras y que se han incorporado a la lengua catalana. En segundo lugar, voy a comentar brevemente aquellos términos -extraídos sólo de la Remenbrança- que he considerado de mayor interés o significativos por alguna causa, incidiendo en la relación o paralelismo, en una palabra, fidelidad del término catalán con el árabe que traduce.

\section{Arabismos:}

Almesch, del árabe misk, actual 'mesc, almesc', castellano 'almizcle'.

Alquitra, del árabe qițrãn, actual 'quitrà', castellano 'alquitrán'.

Ambre, del árabe 'anbar, actual 'ambre', castellano 'ámbar'.

Bellotes, del árabe ballut, actual 'gla, aglà', castellano 'bellota'.

Arop, del árabe rubb, actual 'arrop', castellano 'arrope'.

Festuch, del árabe fustuq, actual 'festuc', castellano 'alfóncigo'.

\section{Utensilios de cocina:}

Padella, actual 'paella, pella', castellano 'sartén'. Traduce el término malla recogido en el original árabe, aunque existen algunas diferencias entre ambos. En realidad, malla es propiamente la fosa en la que se enciende el fuego para cocer el pan sobre las ascuas y cenizas; en al-Andalus tenía el significado genérico de 'horno' y se aplicaba a toda obra de albañilería que utilizaba el panadero para cocer el pan ${ }^{38}$.

Tenor, del árabe tannür, castellano 'atanor'. Aquí es sólo una transcripción, pues no ha pásado al catalán con este significado.

${ }^{38}$ Según A. M. Alcover, la primera documentación es del s. XIV. Cf. Diccionari Català-Valencià-Balear, obra iniciada por Mn. A. M. Alcover, redactat per F. de B. Moll, amb la colaboraciò de M. Sanchis Guarner i A. Moll Marquès, 10 vols., Palma de Mallorea, 1980, VIII, pág. 105, s.v. "paella". 
Forn, aquí con el significado restringido de 'horno público', no aplicable al doméstico. Asf, el texto especifica que el pan se preparará "en lo forn o en la cassa".

Scudella envidriada, el término árabe que traduce, inà' hantam, tiene el significado genérico de 'recipiente de cocina de cerámica vidriada', y no de ninguno en particular como sucede en la traducción catalana; es decir, el de un cuenco de cerámica que permitra tomar alimentos líquidos o semilíquidos y cuyo uso era estrictamente individual. Por otra parte, el Vocabulista in Arabico ${ }^{39}$, s.v. "scutella", incluye varios términos árabes aplicados a las fuentes y lebrillos.

Materias primas:

a) cereales y leguminosas

Pa d'ordi, que es ciuada, 'ordi', del latín hordeu, corresponde al castellano 'cebada'; sin embargo, en romance, el significado primitivo de 'ciuvada' ( < cibata) era el genérico de 'comida de bestias'; este significado debió tener aún la palabra 'civada' en el catalán arcaico, y después de algún tiempo fue adquiriendo el concreto de 'avena' -en castellano 'cebada' tiene el significado concreto de 'ordi'-. Es decir, que en siglo XIV coexisten ambos términos con el mismo significado -cebada-, aunque parece que 'ciuada' estaba más arraigado. El Vocabulista in Arabico traduce sa 'ir, cast. 'cebada', por 'ordeum' ${ }^{40}$.

'Adacça', pa de, catalán 'dacsa, adacsa', castellano 'adaza, zahína'. Comúnmente se le viene aplicando una etimología árabe, aunque hasta ahora ésta no se encuentra bien documentada ${ }^{41}$. En algunos casos se ha pretendido derivarla del árabe 'adasa', castellano

39 Vocabulista in arabico publicado per la primera volta sopra un codice della Biblioteca Riccardiana di Firenze, ed. C. Schiaparelli, Florencia, 1871, pág. 573.

40 Ibidem, pág. 503.

${ }^{41}$ Sobre las dintintas teorías sobre su etimología y significado, véase $\mathrm{A} . \mathrm{M}$. Alcover, Diccionari Catalá, I, pág. 181; J. Coromines, Diccionari etimològic $i$ complementari de la llengua catalana, 9 vols., 5 ed., Barcelona, 1988, III, págs. 9 y 10 . 
'lentejas', teoría que queda descartada. El término árabe que traduce adaça es dura, castellano 'sorgo', mientras que para el Botánico Anónimo Sevillano "dura se llama en 'ayamiyya sayyinna y panichcho ${ }^{142}$.

La Remenbrança de les viandes omite algunos tipos de pan citados en el texto árabe: el de sult (espelta), saylam (cizaña), lübiya (alubias), kirsanna (alcarceña) y qunnab (cañamón), tal vez porque éstos eran cereales que no se cultivaban. Tampoco se alude a los de raíces y semillas, estos últimos totalmente prohibidos por Avenzoar, pero que debieron consumirse en al-Andalus en épocas extremas, como lo demuestran las tajantes palabras de dicho autor sobre estos panes recogidas en el original árabe: "no se deben de consumir en ningún momento ni bajo ningún tipo de circunstancias, ya que resultan nocivos ${ }^{43}$. La omisión de los restantes tipos de pan, los llamados panes de sustitución, todos ellos elaborados con cereales secundarios, puede ser indicativo de que, o el cereal base no se cultivaba de forma extendida en la Corona de Aragón, o bien no se acostumbraba a emplearlos para el consumo humano.

b) platos elaborados a base de cereales y leguminosas

En el apartado de las preparaciones culinarias, concretamente en éste de las sopas espesas y gachas, es donde existe una mayor confusión, ya que en la mayoría de los casos son nombres de platos específicamente árabes, sin equivalencia o posible traducción a lenguas romances.

Entre estos platos tenemos:

Les uosques, que traduce el término árabe bismăt, castellano 'bizcocho', no con el actual significado de una variedad de dulce, sino

${ }^{42} \mathrm{M}$. Asín Palacios, Glosario de voces romances registradas por un botánico anónimo hispano-musulmán (siglos XI-XIl), Madrid-Granada, 1943, nº 406, págs. 211 y 212.

${ }^{43}$ Kitāb al-agdiya, ed., pág. 13, trad., pág. 49. 
con el de 'pan recocido, cocido por dos veces'. En este sentido el Vocabulista ${ }^{44}$ registra la voz 'biscoctus' como equivalente de bismăt.

Farines cuytes, referidas a la famosa harira, sopa espesa con bastantes especias. En este apartado la versión catalana recoge las dos variedades de hartra citadas por el original árabe: la elaborada con harina de trigo y la de harina de cebada.

Açorda/aforda/sorda, arabe 'al-tarid, al-turda'. El nombre de este plato tampoco ha pasado al catalán, ya que solamente se ha transcrito. El tarid se preparaba con trozos de pan migado -de ahí su nombre, derivado de la raíz tarada, 'migar'- en un caldo más o menos espeso. A veces se le añadía carne, verduras, etc ${ }^{45}$.

Fuera de este grupo de platos básicos, elaborados con cereales y leguminosas, que constituían la dieta habitual de la mayoría de la población, encontramos en la versión romanceada del Kitäb al-agdiya los nombres de otros preparados culinarios que el autor se limita a transcribir.

Por último, quiero subrayar una vez más la importancia de estas traducciones catalanas, fieles exponentes de la incidencia de la producción científica andalusí dentro del panorama cultural de la Corona de Aragón.

${ }^{44}$ Vocabulista in arabico, pág. 38.

${ }^{45}$ Sobre los diferentes tipos de gachas y sopas más o menos espesas, véase E. García Sánchez, "La alimentación en la Andalucía islámica (I)", Andalucía Islámica. Textos y Estudios, II-III (1981-1982), 139-178, especialmentepágs. 168173. 